Article

\title{
Biocatalyzed Reactions towards Functional Food Components 4-Alkylcatechols and Their Analogues
}

\author{
Ludmila Martínková ${ }^{1, *}$, Romana Př́hodová ${ }^{1}$, Natalia Kulik ${ }^{2}$, , Helena Pelantová ${ }^{3}$, \\ Barbora Křístková $^{1}$, Lucie Petrásková ${ }^{1}(\mathbb{D})$ and David Biedermann ${ }^{1}$ (D) \\ 1 Laboratory of Biotransformation, Institute of Microbiology of the Czech Academy of Sciences, \\ Vídeňská 1083, CZ-142 20 Prague, Czech Republic; romana.prihodova@biomed.cas.cz (R.P.); \\ barbora.kristkova@biomed.cas.cz (B.K.); petraskova@biomed.cas.cz (L.P.); biedermann@biomed.cas.cz (D.B.) \\ 2 Centre for Nanobiology and Structural Biology, Institute of Microbiology of the Czech Academy of Sciences, \\ Zámek 136, CZ-373 33 Nové Hrady, Czech Republic; kulik@nh.cas.cz \\ 3 Laboratory of Molecular Structure Characterization, Institute of Microbiology of the Czech Academy of \\ Sciences, Vídeňská 1083, CZ-142 20 Prague, Czech Republic; pelantova@biomed.cas.cz \\ * Correspondence: martinko@biomed.cas.cz; Tel.: +420-296-442-569
}

Received: 30 June 2020; Accepted: 12 September 2020; Published: 18 September 2020

\begin{abstract}
Catechols are antioxidants and radical scavengers with a broad medical potential. 4-Methylcatechol (1b) and 4-ethylcatechol (2b) (occurring in some traditional fermented and smoked foods) activate the cell defense against oxidative stress. We examined the biocatalyzed reactions towards 4- $n$-alkylcatechols with different side chains length, which is a factor important for the biological activities of catechols. 4- $n$-Alkylcatechols with methyl through heptyl side chains (1b-7b) were obtained in one pot by (i) oxidation of phenols 1a-7a with tyrosinase from Agaricus bisporus followed by (ii) reduction of ortho-quinones (intermediates) with L-ascorbic acid sodium salt. The conversions decreased with increasing side chain length. The preparative reactions were carried out with substrates 1a-5a. The isolated yields of the purified products decreased from $59 \%$ in $\mathbf{2 b}$ to $10 \%$ in $\mathbf{5 b}$ in correlation with $\log \mathrm{P}$ of the substrates. Homology modeling indicated that the affinities of two tyrosinase isoforms (PPO3 and PPO4) to the substrates with side chains longer than C2 decreased with increasing side chain length. This was probably due to steric limitations and to missing interactions of the extended side chains in the active sites. We envisage using the model to predict further substrates of tyrosinase and testing the products, catechols, for radical-scavenging and biological activities.
\end{abstract}

Keywords: biocatalyzed reaction; tyrosinase; alkylphenol; alkylcatechol; functional food; homology modeling; ligand docking

\section{Introduction}

A number of natural ortho-diphenols (catechols) and their synthetic derivatives (Scheme 1) exhibit biological effects, which can be assigned to free radical scavenging or metal ion binding [1]. For instance, piceatannol was shown to have radical ( $\mathrm{HO} \cdot$ and $t$-BuOO$\cdot)$ and singlet oxygen $\left({ }^{1} \mathrm{O}_{2}\right)$ scavenging activities several times higher than resveratrol or Trolox [2] and also to exhibit immunosuppressive, anticancer, antiinflammatory and anticolitic effects [3]. Protocatechuic aldehyde (3,4-dihydroxybenzaldehyde) exhibited antioxidant and anticancer effects and prevented experimental pulmonary fibrosis [4]. Carnosic acid and its analogues were found to have, e.g., antiproliferative, antimutagenic, antifungal or antiviral properties [5]. Antiviral activities were also reported in brominated catechols such as lanosol [6], a diterpenoid-like catechol [7] or dihydroxychromone catechols [8]. Recently, some 4-alkylcatechols (4-methylcatechol, 4-ethylcatechol and 4-vinylcatechol) were reported to induced the 
cell response to oxidative stress. They are present in some traditional foods preserved by fermentation with lactobacilli or by wood smoke ("functional foods") but they are largely missing in current Western diets [9].

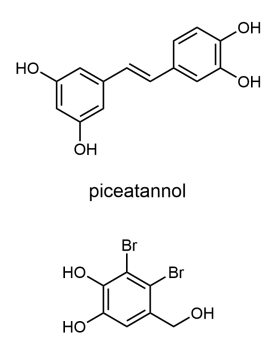

lanosol

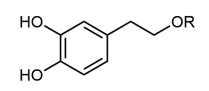
4-hydroxytyrosols
$\mathrm{R}=\mathrm{H}$, acetyl - valeryl

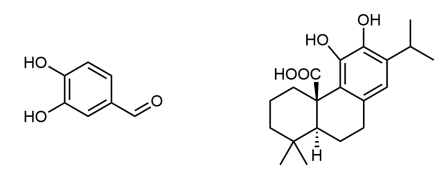

protocatechuic aldehyde carnosic acid

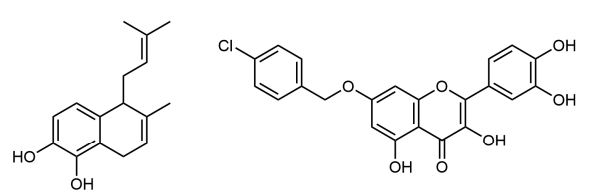

diterpenoid-like catechol

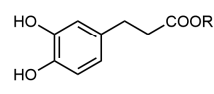

dihydrocaffeoyl catechol $\mathrm{R}=\mathrm{H}$, methyl - butyl dihydroxychromone catechol

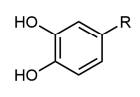

$\mathrm{R}=\mathrm{H}$, catechol

$\mathrm{R}=\mathrm{CH}_{3}, 4$-methylcatechol

$\mathrm{R}=\mathrm{CH}_{2} \mathrm{CH}_{3}$, 4-ethylcatechol
$\mathrm{R}=\mathrm{CHCH}_{2}$, 4-vinylcatechol

Scheme 1. Examples of natural and synthetic catechols with antioxidant or biological activities [1-9].

The ortho-hydroxylation of phenols with tyrosinase is a mild and simple route to catechols [1,10-16]. Tyrosinase (EC 1.14.18.1), also designated polyphenol oxidase (PPO), is an almost ubiquitous dicopper oxidase with activities for phenols and catechols. The oxidation of phenols requires that the catalytic site be in its oxy form $\left(\mathrm{Cu}^{\mathrm{II}}-\mathrm{O}_{2}{ }^{2-}-\mathrm{Cu}^{\mathrm{II}}\right)$. However, catechols are oxidized by both the oxy and the met form $\left(\mathrm{Cu}^{\mathrm{II}}-\mathrm{Cu}^{\mathrm{II}}\right)$. The reaction products obtained from both phenols and catechols are ortho-quinones [17]. The simultaneous reduction of the ortho-quinone with L-ascorbic acid (AA) made it possible to obtain the corresponding catechol in one pot, as proposed for the production of 3,4-dihydroxyphenylethanol (hydroxytyrosol), an antioxidant from olives [10]. 3,4-Dihydroxyphenyl-L-alanine (DOPA), a dopamine precursor used for the treatment of Parkinsonism [11,12], or various other types of catechols [13] was prepared in an analogous way. The route to hydroxytyrosol was recently improved by reducing the ortho-quinone with $\mathrm{NADH}$, which was regenerated with a glucose dehydrogenase [18]. A modified route consisted of two separate steps; in the first step an immobilized tyrosinase catalyzed the transformation of monophenols into ortho-quinones, which were then reduced with dithionite [1] or sodium sulfite [14]. This approach enabled one to obtain, e.g., some esters of hydroxytyrosol and dihydrocaffeoyl catechols (moderate antiviral agents) [1], as well as DOPA-containing peptides [16].

In addition, various 4-alkylphenols were found to be substrates of tyrosinase in bioremediation studies $[19,20]$. The reactions were carried out without a reducing agent, resulting in the formation of ortho-quinones, which were removed by adsorption to chitosan. This demonstrated reactivity of phenols with extended side chains up to $n$-nonyl [20], although the products were not reduced to catechol or isolated.

We became interested in 4- $n$-alkylcatechols, two of which (methyl- and ethylcatechol) were found to act against cell oxidative stress (see above). It is plausible that the side chain length will influence the biological activities of these compounds like in other catechols [1]. The first aim of our study was to examine the effect of the side chain length on the reactivity of $n$-alkylphenols in the aforementioned biocatalyzed reactions. The second aim was to obtain the pure $n$-alkylcatechols for future radical scavenging and biological activity testing. The reactivities of the phenols were studied both in vitro and in silico. The latter approach consisted of docking the alkylphenol ligands in the active sites of two tyrosinases isoenzymes, PPO3 and PPO4. By comparing the resulting binding poses with in vitro substrate conversions, we evaluated the utility of the models for predicting tyrosinase substrates. In addition, catechols $\mathbf{1} \mathbf{b}-\mathbf{5 b}$ were prepared in purities suitable for future testing. 


\section{Results and Discussion}

The abilities of the mushroom tyrosinase (Sigma) to catalyze the ortho-hydroxylation of 4-alkylphenols 1a-7a in the presence of L-ascorbic acid sodium salt (AASS) were compared. The reaction was proposed to consist of phenol oxidation by tyrosinase coupled to the reduction of the intermediate quinone (Scheme 2), similar to previous hypotheses on this reaction type $[10,13]$.

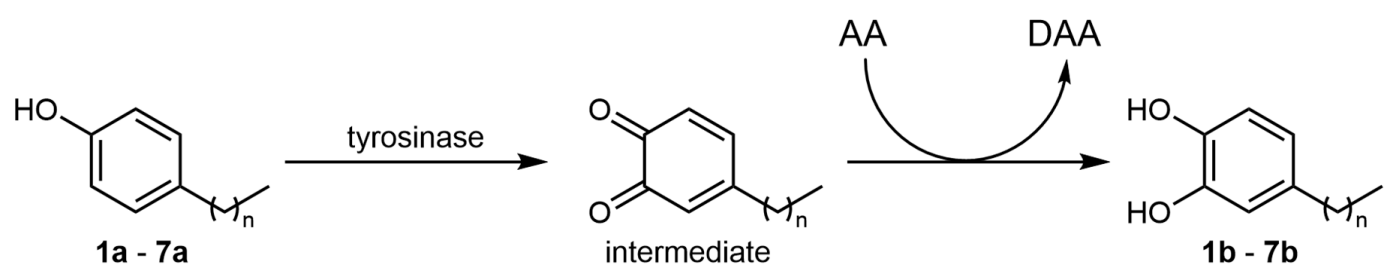

Scheme 2. Proposed mechanism of the ortho-hydroxylation of 4-n-alkylphenols using tyrosinase and a reducing agent (AA) according to [10,13]; $\mathbf{1 a}, \mathbf{b}: n=0 ; \mathbf{2 a}, \mathbf{b}: n=1 ; 3 \mathbf{a}, \mathbf{b}: n=2 ; \mathbf{4 a}, \mathbf{b}: n=3 ; \mathbf{a} \mathbf{a}, \mathbf{b}: n=4$; 6a, b: $n=5 ; \mathbf{7 a}, \mathbf{b}: n=6$; AA: L-ascorbic acid, DAA: L-dehydroascorbic acid.

The substrate screening was performed on an analytical scale $(0.5 \mathrm{~mL})$. The composition of the reaction mixtures ( $5 \mathrm{mM}$ substrate, $30 \mathrm{mM}$ AA sodium salt (AASS) as the reducing agent and HPLC grade water) resulted from the examination of the effects of the substrate, AA or AASS, and enzyme concentrations, and the reaction medium (Appendix A).

The substrate conversion was monitored by HPLC. The conversions were between $70 \%$ and $80 \%$ in $\mathbf{1 a}-\mathbf{3 a}$ and around $50 \%$ in $\mathbf{4 a}$ and $\mathbf{5 a}$ after $1 \mathrm{~h}$ reactions. Substrates $6 \mathbf{a}$ and $7 \mathbf{a}$ reacted at lower rates with conversions of $33 \%$ and $24 \%$, respectively, after $5 \mathrm{~h}$. This can be at least partly explained by the hydrophobicity of these substrates, $\log P$ increasing with increasing side chain length (Table 1 ). However, phenol was also an inferior substrate with only ca. $24 \%$ conversion after $1 \mathrm{~h}$. Each substrate was transformed into a major product, which was more polar than the substrate. The retention times (RTs) and spectral maxima of the products were in agreement with those of authentic standards available for $\mathbf{1 b}$ and $\mathbf{2 b}$ (Table S1 in Supplementary Materials). LC-MS confirmed the expected molecular masses of the products $\mathbf{1 b}-\mathbf{7 b}$ (Table S2 in Supplementary Materials). Isomers of 4-methylphenol (1a), i.e., 2- and 3-methylphenol, were also among the tested compounds. However, the former was not transformed into any detectable product and the latter reacted sluggishly. Substrates 1a-5a were selected for preparative reactions on the $160 \mathrm{~mL}(0.8 \mathrm{mmol})$ scale.

Table 1. Biocatalyzed transformations of 4-alkylphenols 1a-5a into 4-alkylcatechols $\mathbf{1 b}-\mathbf{5 b}$.

\begin{tabular}{cccc}
\hline Substrate & ${\mathbf{~} \mathbf{l o g} \mathbf{P}^{\mathbf{1}}}$ & Reaction Time [h] & Product (Amount; Isolated Yield) ${ }^{\mathbf{2}}$ \\
\hline 4-methylphenol (1a) & 1.94 & 3 & $\mathbf{1 b}(45 \mathrm{mg} ; 45 \%)$ \\
4-ethylphenol (2a) & 2.58 & 4 & $\mathbf{2 b}(65 \mathrm{mg} ; 59 \%)$ \\
4-propylphenol (3a) & 3.20 & 4.5 & $\mathbf{3 b}(46 \mathrm{mg} ; 45 \%)$ \\
4-butylphenol (4a) & 3.65 & 4.5 & $\mathbf{4 b}(34 \mathrm{mg} ; 28 \%)$ \\
4-pentylphenol (5a) & 4.06 & 4.5 & $\mathbf{5 b}(15 \mathrm{mg} ; 10 \%)$ \\
\hline
\end{tabular}

1 https://pubchem.ncbi.nlm.nih.gov (accessed on 17 August 2020); ${ }^{2}$ Purified by low-pressure silica gel column chromatography followed by preparative HPLC (Materials and Methods).

In order to reduce the catalyst cost, the tyrosinase from Sigma was replaced with a crude tyrosinase prepared from fruiting bodies of the common button mushroom, Agaricus bisporus. The crude enzyme exhibited specific activities of $0.20 \pm 0.05 \mathrm{U} \mathrm{mg}^{-1}$ of protein, i.e., almost six times lower than the commercial tyrosinase with $1.11 \pm 0.30 \mathrm{U} \mathrm{mg}^{-1}$ of protein with DOPA as the substrate. This necessitated increasing the enzyme loads proportionately. The suitability of the crude enzyme was first examined with substrate 1a on a $0.5 \mathrm{~mL}$ scale and the reaction was compared with that catalyzed with the same amount of activity of the commercial tyrosinase. At intervals, samples were withdrawn to 
determine the concentrations of substrate $\mathbf{1} \mathbf{a}$, product $\mathbf{1} \mathbf{b}$ and AASS (Figure 1 ). The rates of substrate consumption decreased with time, reflecting possible enzyme deactivation. Actually, the transformation of the tyrosinase oxy form into the deact form $\left(\mathrm{Cu}^{\mathrm{II}}-\mathrm{Cu}^{0}\right)$ occurs upon processing of catechols by the former [17]. The reaction catalyzed by the commercial tyrosinase was faster than that catalyzed by the crude tyrosinase in the initial reaction stages. However, the former ceased earlier within the reaction time. Thus the maximum conversions were similar with $81 \%$ for the commercial tyrosinase after $60 \mathrm{~min}$ and $72 \%$ for the crude tyrosinase after $90 \mathrm{~min}$. Although added at excess, AASS was almost exhausted at the end of the reactions. However, increasing the concentration of AASS from $30 \mathrm{mM}$ up to $120 \mathrm{mM}$ did not increase the conversions (Appendix A). The possible effect of feeding AASS remains to be examined. Reactions without AASS were run as controls. Mixtures of products were detected by HPLC in these reactions (not shown). These products were probably formed by the spontaneous reactions of the ortho-quinone intermediate.
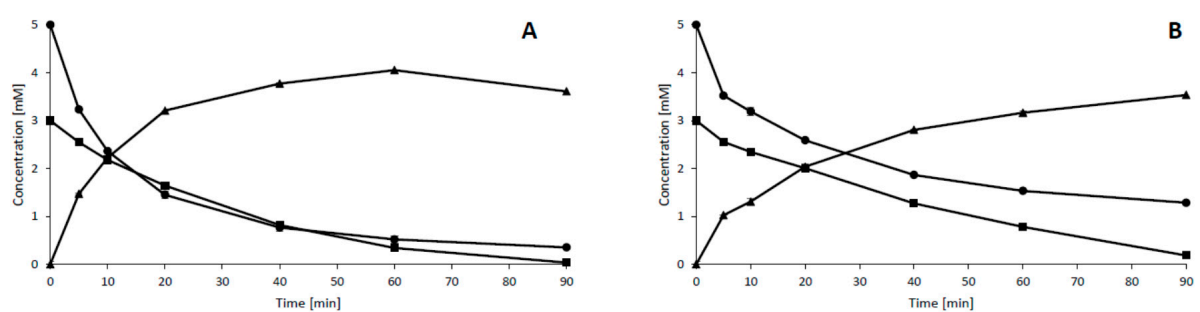

Figure 1. Tyrosinase-catalyzed reactions of $1 \mathrm{a}(5 \mathrm{mM})$ using $(\mathbf{A})$ commercial tyrosinase or $(\mathbf{B})$ crude tyrosinase with $30 \mathrm{mM}$ L-ascorbic acid sodium salt (AASS). The concentrations (mM) of phenol 1a $(\cdot)$, catechol $\mathbf{1 b}(\mathbf{\Delta})$ and AASS $(0.1 \times$ concentration; $\boldsymbol{\square})$ were determined by HPLC. See Materials and Methods for details.

Side activities such as laccase and various glycosidases were previously found in tyrosinase preparations [21]. Especially the laccase activity can deteriorate the performance of the tyrosinase catalyst, as it can lead to substrate and/or product losses through side reactions, which may ultimately lead to the formation of high molecular weight product precipitates. Therefore, we examined the laccase activity of the crude extract used for the preparative reactions. However, we did not detect any laccase activity in this preparation. The absence of the laccase activity was beneficial for using the crude extract in the biocatalyzed reactions.

The preparative-scale reactions had to be prolonged to achieve similar conversions as on analytical scale. This could be due to a different reaction mixture volume and different agitation rate (Materials and Methods), which probably affected the aeration. The products were extracted with ethyl acetate, concentrated and purified using low pressure silica gel column (flash) chromatography followed by preparative HPLC. This two-step purification protocol was used in order to get the products in high purity for future radical scavenging and other potential (biological) tests. The isolated yields of the products were acceptable (28-59\%) except for the low yield of $5 \mathbf{b}(10 \%$; Table 1$)$. The product structures were confirmed by ${ }^{1} \mathrm{H}$ and ${ }^{13} \mathrm{C}$ NMR (Appendix A). The isolated yields of products only purified by flash chromatography were $10-20 \%$ higher but some impurities were detected by NMR (data not shown).

Previously, Yamada [19] described the transformations of $0.5 \mathrm{mM}$ phenols 1a-4a, 3-methylphenol and 4-tert-butylphenol by tyrosinase. The products, ortho-quinones, were determined spectrophotometrically and, optionally, adsorbed to chitosan. A full conversion was achieved for $1 \mathbf{a}$ through $\mathbf{4 a}$, while the reaction time needed to reach that conversion increased from $9 \mathrm{~min}$ in $1 \mathbf{a}$ to $20 \mathrm{~min}$ in 3a and 4a. 3-Methylphenol required $60 \mathrm{~min}$ for an almost full conversion. Thus the effect of the side chains on the reactivity of the phenols was similar as in our study, although the final products were of different types. Substituted phenols with longer or branched side chains (n-pentyl through n-nonyl, 4-isopropyl, 4-sec-butyl and 4-tert-pentyl) were also tyrosinase substrates but the reactions of 
these substrates were performed at low substrate concentrations from $0.05 \mathrm{mM}$ of 4 - $n$-octylphenol and 4-n-nonylphenol to $0.5 \mathrm{mM}$ of e.g., $n$-pentylphenol. Particularly 4-n-nonylphenol required longer reaction times of almost $120 \mathrm{~min}$ [20]. This confirms the aforementioned trend.

In the next part of the study, we aimed at comparing the above results with in silico modeling of the alkylphenol interactions in the active site of tyrosinase. To this end, tyrosinase isoforms PPO3 and PPO4 were constructed (see Materials and Methods). These isoenzymes are two of at least five tyrosinases PPO1-PPO5 in A. bisporus [22] but the crystal structures of PPO3 and PPO4 were the only ones solved [23,24]. The substrate interactions with the active site residues and cofactor atoms were described; the binding poses were then evaluated by molecular dynamics (MD) simulation.

The two peroxide oxygens of the active site were designated "proximal" (O1) and "distal" (O2) as in the tyrosinase from Streptomyces [25]. In PPO3, all substrates but phenol had hydroxyl hydrogen closer to $\mathrm{O} 1$ than to O2. Phenol rotated during MD simulations (see Materials and Methods) to reach an orientation with hydroxyl that was almost equidistant to O1 and O2 (Table S3). In contrast, in PPO4 the hydroxyl hydrogen was almost equidistant to $\mathrm{O} 1$ and $\mathrm{O} 2$ in all substrates. The mutual orientation of the hydrogen bond (HB) donor-acceptor in PPO4-ligand systems allowed $\mathrm{HB}$ formation with $\mathrm{O} 1$ and $\mathrm{O} 2$, while in PPO3 the ligands were closer to $\mathrm{O} 1$ and could only form a HB with O1. A small distance to both peroxide oxygens is important for the deprotonation of the substrate by the cofactor [25]. Distances from copper ions to the His residues coordinating them were conserved during MD and similar for all MD simulations (Table S4 in Supplementary Materials).

Other interactions between the ligands and the tyrosinase-cofactor complexes consisted of $\pi-\pi$ interactions (stacking) and hydrophobic interactions. In PPO3, phenol formed $\pi-\pi$ interactions (stacking) with H263 and F264 and hydrophobic interactions with V283, F264 and the methyl group in H263. Thus the position of phenol was stabilized by a hydrophobic interaction with F264 and a T-shaped stacking with the same amino acid (Figure 2A). In this isoenzyme, interactions of $4 \mathbf{a}$ with the active site were different in comparison with phenol, as the stacking with F264 was weaker and an additional hydrophobic interaction with A286 was formed (Figure 2B). The presence of F264 over the phenol binding pocket in PPO3 affected the substrate orientation in the active site (Figure 2C) and limited the flexibility of $4-n$-alkyl phenols with longer side chains. These substrates rotated in the plane of the benzene ring to fit in the binding pocket in PPO3.
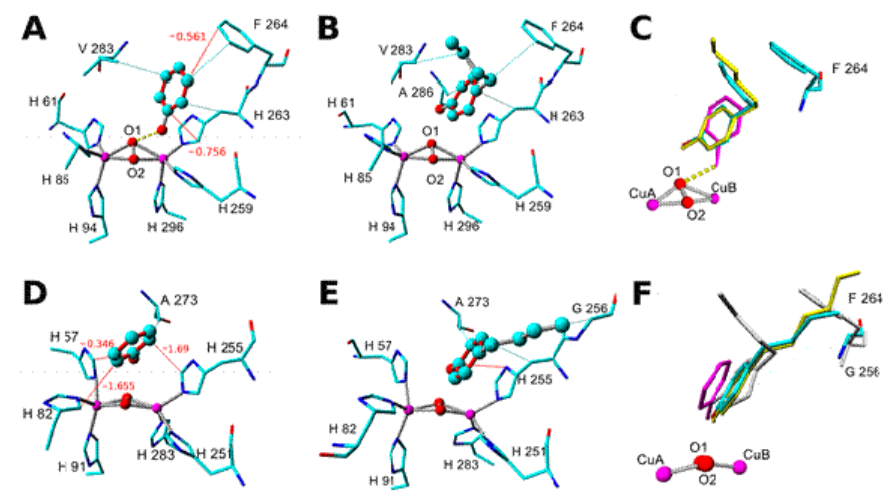

Figure 2. Models of active sites of tyrosinases PPO3 (upper line) and PPO4 (lower line) with docked (A,D) phenol and (B,E) 4- $n$-butylphenol (4a) after $10 \mathrm{~ns}$ of molecular dynamics (MD) simulations. Hydrogens are hidden and oxygen and copper atoms of the cofactor are shown as red and magenta balls, respectively. Amino acids within $3 \AA$ of the ligands are shown; $\pi-\pi$ interactions are depicted as red lines with the energy of the interaction $(\mathrm{kcal} / \mathrm{mol})$ labeled in red (lower energy means a stronger interaction); hydrophobic interactions are shown as cyan lines, connecting interacting groups; hydrogen bonds are shown as yellow dotted lines. (A,B,D,E) Ligands in the element color, ball and stick representation. (C) Overlay of ligand positions in the active site of PPO3 (phenol, magenta; 4a, element; 4- $n$-hexylphenol (6a), yellow). (F) Overlay of ligand positions in the active site of PPO4 (same legend). Additionally the relative orientation of $\mathbf{4 a}$ and F264 in PPO3 is shown in grey. 
In PPO4, the main interactions of phenol consisted of stacking with H57, H82 and H255 (Figure 2D). The interactions with $\mathrm{H} 57$ and H82 were weak. Substrates 2a-4a were shifted away from these residues during MD and only formed a well-defined $\pi-\pi$ stacking with H255 (as shown for 4a in Figure 2E). F264 in PPO3 was replaced by a smaller G256 in PPO4 (Figure 2E,F) and by V in PPO1 and PPO2 [23]. This residue in $\mathrm{PPO} 4$ formed a hydrophobic interaction with the alkyl in 4a (Figure 2E) but did not restrain the ligand flexibility in the active site like in PPO3. V283 in PPO3 was substituted with a smaller A270 (not shown) in PPO4 (with P in PPO1 and PPO2). A286 in PPO3 was conserved in PPO4 as A273 (as well as in PPO1 and PPO2). The differences in the orientation of different 4- $n$-alkylphenols in $\mathrm{PPO} 4$ were thus even more significant than in PPO3-in the former the substrates not only rotated in the plane of the benzene ring but also in the normal to this plane (Figure 2F).

The affinity of PPO3 and PPO4 for their ligands was characterized by binding SP (standard precision) scores (Table 2). Lower scores correspond to a better binding and a higher affinity of the enzyme for the ligand.

Table 2. Binding glide scores calculated for various ligands docked in the active sites of tyrosinases $\mathrm{PPO} 3$ and PPO4.

\begin{tabular}{|c|c|c|c|c|}
\hline \multirow{3}{*}{ Enzyme } & \multirow{3}{*}{ Ligand } & \multicolumn{3}{|c|}{ Binding SP Score (kcal/mol) } \\
\hline & & \multirow{2}{*}{ Before MDS $^{1}$} & \multicolumn{2}{|c|}{ After MDS } \\
\hline & & & After $10 \mathrm{~ns}$ & After $20 \mathrm{~ns}$ \\
\hline \multirow{10}{*}{ PPO3 } & phenol & -6.4 & -5.359 & -5.360 \\
\hline & 2-methylphenol & -6.477 & -5.763 & -5.150 \\
\hline & 3-methylphenol & -6.926 & -5.943 & -6.509 \\
\hline & 4-methylphenol (1a) & -6.880 & -6.465 & -6.245 \\
\hline & 4-ethylphenol (2a) & -6.188 & -6.256 & -6.533 \\
\hline & 4-propylphenol (3a) & -6.120 & -6.02 & -6.05 \\
\hline & 4-butylphenol (4a) & -5.719 & -5.883 & -5.999 \\
\hline & 4-pentylphenol (5a) & -5.337 & -5.132 & -5.079 \\
\hline & 4-hexylphenol (6a) & -5.394 & -5.615 & -5.251 \\
\hline & 4-heptylphenol (7a) & -5.451 & -4.585 & -4.359 \\
\hline \multirow{10}{*}{ PPO4 } & phenol & -5.407 & -5.352 & -5.33 \\
\hline & 2-methylphenol & -5.587 & -4.097 & n.a. ${ }^{2}$ \\
\hline & 3-methylphenol & -5.532 & -5.206 & -5.493 \\
\hline & 4-methylphenol (1a) & -5.479 & -5.218 & -4.244 \\
\hline & 4-ethylphenol (2a) & -5.874 & -5.816 & -5.760 \\
\hline & 4-propylphenol (3a) & -5.303 & -5.39 & -4.88 \\
\hline & 4-butylphenol (4a) & -4.874 & -4.732 & -4.758 \\
\hline & 4-pentylphenol (5a) & -4.645 & -4.410 & -4.326 \\
\hline & 4-hexylphenol (6a) & -4.156 & -4.24 & -4.19 \\
\hline & 4-heptylphenol (7a) & -3.827 & -4.198 & -4.298 \\
\hline
\end{tabular}

${ }^{1}$ MDS $=$ molecular dynamics simulation; ${ }^{2}$ n.a. $=$ not applicable.

The affinity of both isoenzymes for ligands with alkyl chains longer than ethyl generally decreased with chain length. Longer alkyl chains had no interaction partners on the binding site and they were exposed to bulk water (Figures S1 and S2). This also implied sterical limitations for ligand reorientation in the active site during the reaction. In PPO3, 3-methylphenol and 1a-4a were better bound than phenol, as determined for equilibrated complexes after 10-20 ns of MD simulations. However, PPO4 only bound 3-methylphenol and 2a better than phenol in the equilibrated complexes after $20 \mathrm{~ns}$ of MD simulations.

MD simulation and the docking of 3-methylphenol in the active sites of tyrosinases resulted in relatively low (favorable) binding scores. However, the equilibrium orientation of 3-methylphenol hydroxyl in PPO3 and PPO4 was different. While in PPO4 it was similar to 1a (Figure S3A), in PPO3 it 
changed due to the presence of a $\mathrm{CH}-\pi$ interaction between $\mathrm{F} 264$ and the methyl group of the substrate (ESI; Figure S3B) [26].

The binding score of 2-methylphenol rapidly increased during MD. In equilibrated conformation (after 20 ns), this ligand had a higher binding score in PPO3 than the majority of other tested ligands (Table 2). This was due to the ligand rotation in the active site, resulting in the methyl group being positioned close to one of the cofactor oxygens (Figure S4A,B). A hydrophobic group at this position hinders the participation of the cofactor and water in substrate deprotonation [25,27]. In PPO4 the score also increased during equilibration, so that this substrate was released from the active site very rapidly (Figure S4C in Supplementary Materials). It was probably only F264 (Figure 2A-C), which kept the ligand from leaving the active site in PPO3. This explained why the introduction of a hydrophobic group at $\mathrm{C}-2$ in phenol was not accepted by the tyrosinases.

Thus alkylphenols with short to medium side chains were proposed as the best substrates by both the in vitro and in silico approach. In 3-methylphenol, however, the predicted affinity did not fully agree to the results of the "wet" experiments. This could be at least partly explained by the complexity of the tyrosinase from A. bisporus but also by the effect of other steps of the catalytic mechanism on the product formation. The crude tyrosinase is known to contain several isoenzymes; yet only two of them with known crystal structures were used for the modeling. In addition, the solubility of alkylphenols, which decreased with the side-chain length, must be taken into account. However, the differences between the calculations and experimental results were rather minor and the modeling/docking approach largely proved to be reliable.

\section{Materials and Methods}

\subsection{Materials and Chemicals}

Mushroom tyrosinase was purchased from Sigma Aldrich (Merck KGaA, Darmstadt, Germany) or prepared from A. bisporus fruiting bodies purchased at the local market. The protocol described by Romanovskaya [28] was slightly modified: Briefly, $250 \mathrm{~g}$ of mushroom was cut into small pieces and homogenized with $500 \mathrm{~mL}$ of cold distilled water containing $1 \%$ AASS and $0.2 \%$ benzoic acid $\left(60 \mathrm{~min}, 4{ }^{\circ} \mathrm{C}\right)$. The extracted protein was precipitated with ammonium sulfate ( $75 \%$ of saturation), the precipitate was centrifuged at $4{ }^{\circ} \mathrm{C}$, dissolved in $20 \mathrm{~mL}$ of $100 \mathrm{mM} \mathrm{Na} / \mathrm{Na}$ phosphate buffer, $\mathrm{pH} 6.5$ (buffer A) and stored on ice.

Chemicals were purchased from standard commercial sources (1a $\geq 99 \%$, Sigma Aldrich; $\mathbf{1 b} \geq 99 \%$, Sigma Aldrich; 2a $\geq 97 \%$, Alfa Aesar (Ward Hill, MA, USA); $\mathbf{2 b} \geq 98 \%$, Alfa Aesar; 3a $\geq 99 \%$, Sigma Aldrich; $\mathbf{4 a} \geq 98 \%$, Alfa Aesar; $5 \mathbf{a} \geq 98 \%$, Alfa Aesar; $6 \mathbf{a} \geq 98 \%$, Sigma Aldrich; 7a $\geq 98 \%$, Alfa Aesar and AASS $\geq 99 \%$ Carl Roth (Karlsruhe, Germany)).

\subsection{Activity Assays}

The tyrosinase assay described by Selinheimo et al. [29] was slightly modified: Briefly, an appropriate amount of tyrosinase was incubated with L-DOPA $(15 \mathrm{mM})$ in buffer A at room temperature. One unit $(\mathrm{U})$ of the tyrosinase activity was expressed as the amount of enzyme that formed $1 \mu \mathrm{mol}$ of dopachrome $\left(\varepsilon_{475}=3400 \mathrm{M}^{-1} \mathrm{~cm}^{-1}\right) \mathrm{min}^{-1}$. The laccase assay was performed as described previously [30]. Briefly, an appropriate amount of crude extract was incubated with diammonium 2,2'-azinobis[3-ethyl-2,3-dihydrobenzothiazole-6-sulphonate] (ABTS; $0.5 \mathrm{mM}$ ) in $100 \mathrm{mM}$ Na acetate buffer, $\mathrm{pH} 4.5$, at room temperature. One unit $(\mathrm{U})$ of the laccase activity was expressed as the amount of enzyme that oxidized $1 \mu \mathrm{mol}$ of ABTS $\left(\varepsilon_{420}=36,000 \mathrm{M}^{-1} \mathrm{~cm}^{-1}\right) \mathrm{min}^{-1}$. 


\subsection{Biocatalyzed Reactions}

\subsubsection{Reactions on the Analytical Scale}

The protocol described by Espín [10] was slightly modified: The reaction mixtures (total volume $0.5 \mathrm{~mL}$ in $1.5 \mathrm{~mL}$ Eppendorf tubes) consisted of $2.5 \mu \mathrm{mol}$ of substrate, $15 \mu \mathrm{mol}$ of AASS, $0.05 \mathrm{~mL}$ of methanol $(\mathrm{MeOH})$ and HPLC-grade water. The mixture was preincubated at $30^{\circ} \mathrm{C}$ with shaking (Thermomixer Compact Eppendorf (Hamburg, Germany), $850 \mathrm{rpm}$ ) for $5 \mathrm{~min}$. The reaction was started by adding $0.04 \mathrm{U}$ of the enzyme and the mixture was incubated under the same conditions. The reaction was terminated by adding $0.05 \mathrm{~mL}$ of $2 \mathrm{M} \mathrm{HCl}$. MeOH $(0.5 \mathrm{~mL})$ was also added to samples withdrawn from the transformations of $4 \mathbf{a}-7 \mathbf{a}$. The precipitated protein was removed by centrifugation and the supernatants were analyzed by HPLC or LC-MS (see below).

\subsubsection{Reactions on the Preparative Scale}

The preparative scale reactions were carried out analogously with modifications: The reaction mixture $(160 \mathrm{~mL})$ was divided into $50 \mathrm{~mL}$ Falcon tubes containing $20 \mathrm{~mL}$ of the reaction mixture each. The crude extract (Section 3.1.) was used instead of tyrosinase Sigma. After $3 \mathrm{~h} \mathrm{(1a),} 4 \mathrm{~h} \mathrm{(2a)}$ or $4.5 \mathrm{~h}$ (3a-5a) of incubation (Thermomixer Compact Eppendorf, $750 \mathrm{rpm}$ ), $2 \mathrm{~mL}$ of $2 \mathrm{M} \mathrm{HCl}$ was added into each tube and the mixture was centrifuged at $4{ }^{\circ} \mathrm{C}$. The products were isolated and purified as described below.

\subsubsection{Product Isolation}

The pooled supernatants were extracted with ethyl acetate $(3 \times 150 \mathrm{~mL})$. The organic fractions were dried with anhydrous $\mathrm{Na}_{2} \mathrm{SO}_{4}$, filtered and the solvent was removed at reduced pressure. All products were purified by low-pressure silica gel chromatography using a mobile phase consisting of toluene/acetone (8:2) and 1\% of formic acid. The fractions were analyzed by TLC 60 F254 silica gel plates (Merck KGaA, Darmstadt, Germany) with the same mobile phase and the spots were visualized in UV light $(254 \mathrm{~nm})$. Selected fractions were analyzed by HPLC as described below. Fractions containing the product were pooled and concentrated under reduced pressure. Formic acid was removed by co-evaporating with water. The products were purified by preparative HPLC (see below).

\subsubsection{Preparative HPLC}

The purification of the products was performed using an isocratic preparative HPLC system (Shimadzu, Kyoto, Japan) consisting of an LC-8A delivery system, Rheodyne manual injection valve, FRC-10A fraction collector and SPD-20A UV detector connected to a CBM-20A control unit. Products were dissolved in $1 \mathrm{~mL}$ of $\mathrm{MeOH}$ and purified on an Asahipak GS-310 20F (300 mm $\times 20 \mathrm{~mm}$ ) column (Showa Denko Europe, München, Germany) with a mobile phase consisting of $100 \% \mathrm{MeOH}$ at a flow rate of $5 \mathrm{~mL} \mathrm{~min}{ }^{-1}$. Fractions containing the products were pooled and the mobile phase was evaporated at reduced pressure.

\subsection{Analytical Methods}

\subsubsection{Analytical HPLC}

The HPLC system was a Shimadzu Prominence (CBM-20 LITE controller, DGU-20A3R degasser, LC-20AB solvent delivery system, MIXER SUS 20A HPLC mixer, SIL-20AHT autosampler, CTO-20AC column oven and SPD-M20A PDA detector; Shimadzu). Analysis proceeded on a Chromolith SpeedRod $\mathrm{RP}-18 \mathrm{e}(50 \mathrm{~mm} \times 4.6 \mathrm{~mm})$ column (Merck) with a mobile phase consisting of acetonitrile (MeCN), water and $0.1 \% \mathrm{H}_{3} \mathrm{PO}_{4}$ at a flow rate of $2 \mathrm{~mL} \mathrm{~min}^{-1}$ and $34{ }^{\circ} \mathrm{C}$. The $\mathrm{MeCN}$ concentration in the mobile phase was $\mathbf{2 0} \%$ for phenol and $\mathbf{1 a}, 30 \%$ for $\mathbf{2} \mathbf{a}$ and $\mathbf{3 a}, 40 \%$ for $\mathbf{4 a}$ and $\mathbf{5 a}$ and $50 \%$ for $\mathbf{6 a}$ and $\mathbf{7 a}$ (Table S1). The peak areas were read out at the local spectral maxima of the analytes (Table S1). Quantitation was performed using program Labsolutions WS-PDA Version 5 (Shimadzu). 


\subsubsection{LC-MS}

The LC-MS system (Shimadzu) consisted of a DGU-20A3R degasser, LC-20AD solvent delivery system, SIL-20AC autosampler, CTO-10AS column oven, PDA detector SPD-M20A and LC-MS2020 detector. The products were analyzed using a Chromolith RP-C18 (100 $\mathrm{mm} \times 3 \mathrm{~mm}$ ) column (Merck KGaA, Darmstadt, Germany) at a flow rate of $0.4 \mathrm{~mL} \mathrm{~min}^{-1}$ in the gradient mode (mobile phase A: $\mathrm{MeCN} /$ water, 5/95, 0.1\% formic acid; mobile phase B: MeCN/water, 80/20, 0.1\% formic acid;\% B 20, 60, 60 and 20 at 0, 3, 8 and $9 \mathrm{~min}$, respectively). The MS detector parameters were as described previously [31]. Quantitation and molecular mass determination proceeded using the program Labsolutions Version 5.75 SP2 (Shimadzu).

\subsubsection{NMR}

Nuclear magnetic resonance (NMR) spectra of $1 b-5 b$ were recorded using a Bruker AVANCE III $400 \mathrm{MHz}$ spectrometer $\left(399.87 \mathrm{MHz}\right.$ for ${ }^{1} \mathrm{H}$ and $100.55 \mathrm{MHz}$ for ${ }^{13} \mathrm{C}$; Bruker BioSpin, Rheinstetten, Germany) equipped with the standard manufacturer's software. The experiments $\left({ }^{1} \mathrm{H} N M R,{ }^{13} \mathrm{C} \mathrm{NMR}\right.$, gCOSY, ${ }^{1} \mathrm{H}_{-}{ }^{13} \mathrm{C}$ gHSQC and ${ }^{1} \mathrm{H}_{-}{ }^{13} \mathrm{C}$ gHMBC) were performed in MeOD at $30{ }^{\circ} \mathrm{C}$. The residual signal of $\mathrm{MeOD}\left(\delta_{\mathrm{H}} 3.306 \mathrm{ppm}\right.$ and $\left.\delta_{\mathrm{C}} 49.05 \mathrm{ppm}\right)$ was used as the internal standard.

\subsection{Molecular Modeling and Ligand Docking}

PDB structures of the crystallized A. bisporus tyrosinases PPO3 (2y9w; [23]) and PPO4 (4oua; [24]) were downloaded from the PDB database and used for MD simulations [32]. Water molecules in the active site were deleted from the structures in YASARA [33]. The C-terminal domain was deleted from the PPO3 structure. A structural alignment with the structure of the crystallized tyrosinase from Streptomyces castaneoglobisporus (1wx2) [34] in YASARA was used to add peroxide oxygen to the active sites of PPO3 and PPO4. The orientation of the cofactor was optimized by quantum mechanics/molecular mechanics (QM/MM) optimization with Qsite in Schrödinger [35], where the cofactor was included in QM and the protein in MM parts (DFT-B3LYP method, lacvp** basis set).

The ligand structures were downloaded from the PubChem database [36] and optimized in YASARA. The stability of the docking pose was validated using root-mean-square displacement (RMSD) values. Constant RMSD values for enzymes were achieved after molecular dynamics (MD) simulation times of $2 \mathrm{~ns}$ for most ligands (Figure S5A,C). Only PPO4 with phenol and 2-methylphenol exhibited a small increase in RMSD after a longer simulation time (20 ns). The most flexible regions are depicted with time averaged structures using the estimation of their B-factors (Figure S5B,D). The observed flexibility did not interfere with ligand binding, as it was only found in the loop regions.

The binding of ligands in active sites was characterized using the Glide SP scores according to a flexible ligand docking protocol (Schrödinger, LLC). The best-scored poses with orientation similar to tropolone (2-hydroxy-2,4,6-cycloheptatrien-1-one; inhibitor of tyrosinase) in the active site of PPO3 were selected and used for MD simulations in YASARA. Ligands were parameterized using the AutoSMILES algorithm. The MD simulation parameters were as follows: TIP3 water, NPT ensemble, long-range electrostatic interactions calculated using the Particle Mesh Ewald algorithm and periodic boundary conditions. Weak restraints were applied on the $\mathrm{Cu}_{2} \mathrm{O}_{2}{ }^{2+}$ complex to keep the cofactor in the active site. The enzyme-ligand complexes after MD simulations were analyzed with YASARA macros and visualized in YASARA, Visual Molecular Dynamics (VMD; [37]) and Xmgrace [38].

\section{Conclusions}

This study demonstrated the usefulness of mushroom tyrosinase for the ortho-hydroxylation of 4- $n$-alkylphenols with various side-chain lengths. The presence of the reducing agent (here AASS) was essential for the conversion of the hypothesized intermediate, ortho-quinone, into the required catechol product. Thus, transformations of all phenols examined (with up to $n$-heptyl side chain) were feasible on the analytical scale. Phenols with up to $n$-pentyl side chain $(\mathbf{1 a}-\mathbf{5 a})$ were transformed at the preparative 
scale; transformations of substrates $6 \mathbf{a}-7 \mathbf{a}$ require some further optimization. The transformation of phenols to catechols with a cheap catalyst means a significant valorization of the starting material, as the prices of the products are much higher than those of the substrates (e.g., 380 EUR for $5 \mathrm{~g}$ of product $2 \mathbf{b}$ and 60 EUR for $250 \mathrm{~g}$ of substrate $2 \mathbf{a}$; VWR ${ }^{\mathrm{TM}}$; https://cz.vwr.com; accessed on 8.8.2020). This proposed reaction and product purification protocol would serve to prepare alkylcatechols for antiradical scavenging tests and biological tests at reasonable costs and suitable purities. It is justified to expect that the side-chain length will influence the biological properties of the compounds as, e.g., in the derivatives of hydroxytyrosol or dihydrocaffeic acid (antiviral agents) [1]. The use of the selected compounds as nature-identical additives in functional foods (e.g., compounds $\mathbf{1 b}, \mathbf{2 b}$ ), potential nutraceuticals or pharmaceuticals may be envisaged. The computational approach will enable us to predict, with some degree of certainty, the tyrosinase activities for other phenol substrates, which may be also used as starting materials for the preparation of high-added-valued building blocks for organic synthesis.

Supplementary Materials: The following are available online at http://www.mdpi.com/2073-4344/10/9/1077/s1, Figure S1: (A-J) Schemes of ligands in the active site of PPO3 after 20 ns MD simulations, (K) Change in solvent-exposed surface of ligands during $20 \mathrm{~ns}$ of MD simulations in the active site of PPO3, Figure S2: (A-J) Schemes of ligands in the active site of PPO4 after $20 \mathrm{~ns}$ of MD simulations, (K) Change in solvent-exposed surface of ligands during $20 \mathrm{~ns}$ of MD simulation in the active site of PPO4, Figure S3: (A) Alignment of corresponding positions of 4-methylphenol and 3-methylphenol in the active site of PPO3 after $20 \mathrm{~ns}$ of MD simulations, (B) Alignment of corresponding positions of 4-methylphenol and 3-methylphenol in the active site of PPO4 after 20 ns of MD simulations, Figure S4: (A) Equilibrated orientation of 2-methylphenol in the active site of PPO3 overlayed with orientation of 4-methylphenol, (B) Water penetration close to the cofactor in the complex of PPO3 with 2-methylphenol, (C) Increase in distance to peroxide oxygens in PPO4-phenol and PPO4-2-methylphenol complexes as a result of ligand rotation, Figure S5: $(\mathrm{A}, \mathrm{C})$ Root-mean-square displacement (RMSD) of protein $\mathrm{C}$ - $\alpha$-atoms calculated during $20 \mathrm{~ns}$ of MD simulations of PPO4 and PPO3, (B,D) Overlay of average structure from MD simulations of PPO4-phenol system and PPO3-4-n-butylphenol system, Table S1: Retention times (RTs) and local absorption maxima of phenol and alkylphenols 1a-7a and the corresponding alkyl catechols $1 \mathbf{b}-7 \mathbf{b}$ in analytical HPLC, Table S2: MS data of compounds $1 \mathbf{b}-7 \mathbf{b}$, Table S3: Average distances of the hydroxyl hydrogens in alkylphenols (ligands) from the oxygen atoms of the $\left[\mathrm{Cu}_{2} \mathrm{O}_{2}\right]^{2+}$ cofactor in tyrosinases PPO3 and PPO4, Table S4: Average distances between $\mathrm{CuA}$ or $\mathrm{CuB}$ and the coordinating His residues in PPO3 and PPO4 isoenzymes.

Author Contributions: Conceptualization, L.M. and N.K.; methodology, L.M., D.B., H.P., L.P. and N.K.; validation, L.M., D.B., H.P. and N.K.; formal analysis, L.M., R.P. and B.K.; investigation, R.P., B.K., H.P., L.P. and N.K.; data curation, L.M., D.B., H.P., L.P. and N.K.; writing-original draft preparation, L.M. and N.K.; writing-review and editing, L.M., N.K., D.B., R.P. and B.K.; project administration, L.M.; funding acquisition, L.M. All authors have read and agreed to the published version of the manuscript.

Funding: This research was funded by Czech Ministry of Education, Youth and Sports, grant numbers LTC 18080 and LTC19037.

Conflicts of Interest: The authors declare no conflict of interest.

\section{Appendix A.}

Appendix A.1. ${ }^{1}$ H and ${ }^{13} \mathrm{C}$ NMR Spectrum of the Products

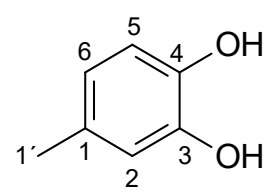

Figure A1. 4-methylcatechol (1b). ${ }^{1} \mathrm{H}$ NMR (399.87 MHz, DMSO- $\left.d_{6}, 30{ }^{\circ} \mathrm{C}\right): 2.108(3 \mathrm{H}, \mathrm{dd}, J=0.7$, $\left.0.5 \mathrm{~Hz}, \mathrm{H}-1^{\prime}\right), 6.388(1 \mathrm{H}, \mathrm{ddq}, J=7.9,2.1,0.7 \mathrm{~Hz}, \mathrm{H}-6), 6.547(1 \mathrm{H}, \mathrm{dq}, J=2.1,0.5 \mathrm{~Hz}, \mathrm{H}-2), 6.598(1 \mathrm{H}, \mathrm{d}$, $J=7.9 \mathrm{~Hz}, \mathrm{H}-5), 8.556\left(2 \mathrm{H}\right.$, br s, 3,4-OH). ${ }^{13} \mathrm{C}$ NMR $\left(100.55 \mathrm{MHz}\right.$ for, DMSO-d $\left.6,30{ }^{\circ} \mathrm{C}\right): 20.31\left(\mathrm{C}-1^{\prime}\right)$, 115.45 (C-5), 116.40 (C-2), 119.49 (C-6), 127.92 (C-1), 142.83 (C-4), 144.96 (C-3). 
<smiles>CC(C)c1ccc(O)c(O)c1</smiles>

Figure A2. 4-ethylcatechol (2b). ${ }^{1} \mathrm{H}$ NMR $\left(399.87 \mathrm{MHz}, \mathrm{DMSO}-d_{6}, 30{ }^{\circ} \mathrm{C}\right): 1.092\left(3 \mathrm{H}, \mathrm{t}, J=7.6 \mathrm{~Hz}, \mathrm{H}-2^{\prime}\right)$, $2.408\left(2 \mathrm{H}, \mathrm{q}, J=7.6 \mathrm{~Hz}, \mathrm{H}-1^{\prime}\right), 6.418(1 \mathrm{H}, \mathrm{dd}, J=8.0,2.1 \mathrm{~Hz}, \mathrm{H}-6), 6.553(1 \mathrm{H}, \mathrm{d}, J=2.1 \mathrm{~Hz}, \mathrm{H}-2), 6.610$ $(1 \mathrm{H}, \mathrm{d}, J=8.0 \mathrm{~Hz}, \mathrm{H}-5) ; 3,4-\mathrm{OH}$ not detected. ${ }^{13} \mathrm{C}$ NMR (100.55 MHz, DMSO-d $\left.6,30{ }^{\circ} \mathrm{C}\right): 15.85\left(\mathrm{C}-2^{\prime}\right)$, 27.45 (C-1'), 115.11 (C-2), 115.39 (C-5), 118.15 (C-6), 134.57 (C-1), 142.99 (C-4), 144.95 (C-3).<smiles>CCC(C)c1ccc(O)c(O)c1</smiles>

Figure A3. 4- $n$-propylcatechol (3b). ${ }^{1} \mathrm{H}$ NMR $\left(399.87 \mathrm{MHz}, \mathrm{DMSO}-d_{6}, 30{ }^{\circ} \mathrm{C}\right): 0.855(3 \mathrm{H}, \mathrm{t}, J=7.3 \mathrm{~Hz}$, H-3'), $1.502\left(2 \mathrm{H}, \mathrm{m}, \mathrm{H}-2^{\prime}\right), 2.363\left(2 \mathrm{H}, \mathrm{m}, \mathrm{H}-1^{\prime}\right), 6.409(1 \mathrm{H}, \mathrm{dd}, J=8.0,2.1 \mathrm{~Hz}, \mathrm{H}-6), 6.562(1 \mathrm{H}, \mathrm{d}, J=2.1 \mathrm{~Hz}$, $\mathrm{H}-2), 6.627(1 \mathrm{H}, \mathrm{d}, J=8.0 \mathrm{~Hz}, \mathrm{H}-5) ; 3,4-\mathrm{OH}$ not detected. ${ }^{13} \mathrm{C} \mathrm{NMR}\left(100.55 \mathrm{MHz}, \mathrm{DMSO}-d_{6}, 30{ }^{\circ} \mathrm{C}\right)$ : 13.55 (C-3'), 24.24 (C-2'), 36.66 (C-1'), 115.33 (C-5), 115.67 (C-2), 118.83 (C-6), 132.91 (C-1), 143.03 (C-4), $144.88(\mathrm{C}-3)$.<smiles>CCCC(C)c1ccc(O)c(O)c1</smiles>

Figure A4. 4- $n$-butylcatechol (4b). ${ }^{1} \mathrm{H}$ NMR (399.87 MHz, DMSO- $\left.d_{6}, 30{ }^{\circ} \mathrm{C}\right): 0.873(3 \mathrm{H}, \mathrm{t}, J=7.3 \mathrm{~Hz}$, H-4' $), 2.270\left(2 \mathrm{H}, \mathrm{m}, \mathrm{H}-3^{\prime}\right), 1.468\left(2 \mathrm{H}, \mathrm{m}, \mathrm{H}-2^{\prime}\right), 2.388\left(2 \mathrm{H}, \mathrm{m}, \mathrm{H}-1^{\prime}\right), 6.407(1 \mathrm{H}, \mathrm{dd}, J=8.0,2.1 \mathrm{~Hz}$, H-6), $6.560(1 \mathrm{H}, \mathrm{d}, J=2.1 \mathrm{~Hz}, \mathrm{H}-2), 6.621(1 \mathrm{H}, \mathrm{d}, J=8.0 \mathrm{~Hz}, \mathrm{H}-5), 8.563$ (2H, br s, 3,4-OH). ${ }^{13} \mathrm{C}$ NMR $\left(100.55 \mathrm{MHz}, \mathrm{DMSO}-d_{6}, 30{ }^{\circ} \mathrm{C}\right): 13.73\left(\mathrm{C}-4^{\prime}\right), 21.64\left(\mathrm{C}-3^{\prime}\right), 33.37\left(\mathrm{C}-2^{\prime}\right), 34.16\left(\mathrm{C}-1^{\prime}\right), 115.34$ (C-5), 115.61 (C-2), 118.76 (C-6), 133.09 (C-1), 142.98 (C-4), 144.89 (C-3).<smiles>C[C]CCCC(I)c1ccc(O)c(O)c1</smiles>

Figure A5. 4- $n$-pentylcatechol (5b). ${ }^{1} \mathrm{H}$ NMR $\left(399.87 \mathrm{MHz}, \mathrm{DMSO}-d_{6}, 30^{\circ} \mathrm{C}\right): 0.850(3 \mathrm{H}, \mathrm{m}, J=7.1 \mathrm{~Hz}$, H-5 $), 1.24^{\mathrm{H}}\left(2 \mathrm{H}, \mathrm{m}, \mathrm{H}-3^{\prime}\right), 1.28^{\mathrm{H}}\left(2 \mathrm{H}, \mathrm{m}, \mathrm{H}-4^{\prime}\right), 1.483\left(2 \mathrm{H}, \mathrm{m}, \mathrm{H}-2^{\prime}\right), 2.377\left(2 \mathrm{H}, \mathrm{m}, \mathrm{H}-1^{\prime}\right), 6.402(1 \mathrm{H}, \mathrm{dd}$, $J=8.0,2.1 \mathrm{~Hz}, \mathrm{H}-6), 6.552(1 \mathrm{H}, \mathrm{d}, J=2.1 \mathrm{~Hz}, \mathrm{H}-2), 6.613(1 \mathrm{H}, \mathrm{d}, J=8.0 \mathrm{~Hz}, \mathrm{H}-5), 8.561(2 \mathrm{H}, \mathrm{br} \mathrm{s}, 3,4-\mathrm{OH})$; ${ }^{\mathrm{H}} \mathrm{HSQC}$ readout. ${ }^{13} \mathrm{C}$ NMR $\left(100.55 \mathrm{MHz}, \mathrm{DMSO}-d_{6}, 30^{\circ} \mathrm{C}\right): 13.83\left(\mathrm{C}-5^{\prime}\right), 21.91\left(\mathrm{C}-4^{\prime}\right), 30.79\left(\mathrm{C}-3^{\prime}\right), 30.81$ (C-2'), 34.42 (C-1'), 115.31 (C-5), 115.58 (C-2), 118.72 (C-6), 133.08 (C-1), 142.96 (C-4), 144.86 (C-3).

Appendix A.2. Effect of Substrate and Ascorbic Acid Concentrations on the Biocatalyzed Reactions

These effects were examined with $1 \mathbf{a}$ as the substrate on the $0.5 \mathrm{~mL}$ scale (Section 3.3.1). The initial conditions were set at $5 \mathrm{mM}$ substrate and $30 \mathrm{mM}$ AA in buffer A (Section 3.1). Buffer A was replaced with HPLC grade water and AA with AASS without compromising the conversions (87-89\%) significantly. This was favorable for LC-MS analysis, buffer A (phosphate) interfering with LC-MS. Increasing substrate concentration from 5 to $10 \mathrm{mM}$ decreased conversion from ca. $84 \%$ to $60 \%$. The concentration of AASS (30-120 mM) did not exhibit a significant effect on the conversions of $5 \mathrm{mM}$ or $10 \mathrm{mM}$ substrate. 
Appendix A.3. Effect of Cosolvents on Tyrosinase Activity and the Biocatalyzed Reactions

The design of the reactions also consisted of a preliminary cosolvent screening. The conversions of $1 \mathbf{a}$ were determined in the reaction mixtures (Section 3.3.1) with $40 \%(v / v)$ of various cosolvents after a 30 min reaction. The conversion decreased in order $\mathrm{MeOH}>\mathrm{EtOH}>$ acetone $>$ DMSO $>$ isopropanol $>\mathrm{MeCN}(38 \%, 32 \%, 29 \%, 27 \%, 18 \%$ and $15 \%$, respectively), while it was $39 \%$ in the standard assay with $10 \% \mathrm{MeOH}$. Analogous experiments were performed with the highly hydrophobic substrate $\mathbf{6 a}$ and some of the best cosolvents $(\mathrm{MeOH}$ and $\mathrm{EtOH})$ but did not demonstrate any significant increase in the conversion of this substrate. Therefore, we conclude that the reactions of the highly hydrophobic $n$-alkylphenols must be further optimized by increasing the concentration of suitable water-miscible cosolvents (e.g., $\mathrm{MeOH}$ ), or by testing water-immiscible cosolvents or ionic liquids.

\section{References}

1. Botta, G.; Bizzarri, B.M.; Garozzo, A.; Timpanaro, R.; Bisignano, B.; Amatore, D.; Palamara, A.T.; Nencioni, L.; Saladino, R. Carbon nanotubes supported tyrosinase in the synthesis of lipophilic hydroxytyrosol and dihydrocaffeoyl catechols with antiviral activity against DNA and RNA viruses. Bioorg. Med. Chem. 2015, 23, 5345-5351. [CrossRef] [PubMed]

2. Sueishi, Y.; Nii, R.; Kakizaki, N. Resveratrol analogues like piceatannol are potent antioxidants as quantitatively demonstrated through the high scavenging ability against reactive oxygen species and methyl radical. Bioorg. Med. Chem. Lett. 2017, 27, 5203-5206. [CrossRef] [PubMed]

3. Yum, S.; Doh, H.-J.; Hong, S.; Jeong, S.; Kim, D.-D.; Park, M.; Jung, Y. Piceatannol, a hydroxystilbene natural product, stabilizes HIF-1 $\alpha$ protein by inhibiting HIF prolyl hydroxylase. Eur. J. Pharmacol. 2013, 699, 124-131. [CrossRef] [PubMed]

4. Zhang, L.; Ji, Y.; Kang, Z.; Lv, C.; Jiang, W. Protocatechuic aldehyde ameliorates experimental pulmonary fibrosis by modulating HMGB1/RAGE pathway. Toxicol. Appl. Pharmacol. 2015, 283, 50-56. [CrossRef] [PubMed]

5. Gigante, B.; Santos, C.; Silva, A.M.; Curto, M.J.M.; Nascimento, M.S.J.; Pinto, E.; Pedro, M.; Cerqueira, F.; Pinto, M.M.; Duarte, M.P.; et al. Catechols from abietic acid: Synthesis and evaluation as bioactive compounds. Bioorg. Med. Chem. 2003, 11, 1631-1638. [CrossRef]

6. Park, S.-H.; Song, J.-H.; Kim, T.; Shin, W.-S.; Park, G.M.; Lee, S.; Kim, Y.-J.; Choi, P.; Kim, H.; Kim, H.-S.; et al. Anti-human rhinoviral activity of polybromocatechol compounds isolated from the Rhodophyta, Neorhodomela aculeata. Mar. Drugs 2012, 10, 2222-2233. [CrossRef]

7. Pawar, R.; Das, T.; Mishra, S.; Nutan; Pancholi, B.; Gupta, S.K.; Bhat, S.V. Synthesis, anti-HIV activity, integrase enzyme inhibition and molecular modeling of catechol, hydroquinone and quinol labdane analogs. Bioorg. Med. Chem. Lett. 2014, 24, 302-307. [CrossRef]

8. Lee, C.; Lee, J.M.; Lee, N.-R.; Kim, D.-E.; Jeong, Y.-J.; Chong, Y. Investigation of the pharmacophore space of Severe Acute Respiratory Syndrome coronavirus (SARS-CoV) NTPase/helicase by dihydroxychromone derivatives. Bioorg. Med. Chem. Lett. 2009, 19, 4538-4541. [CrossRef]

9. Senger, D.R.; Li, D.; Jaminet, S.-C.; Cao, S. Activation of the Nrf2 cell defense pathway by ancient foods: Disease prevention by important molecules and microbes lost from the modern western diet. PLoS ONE 2016, 11, e148042. [CrossRef]

10. Espín, J.C.; Soler-Rivas, C.; Cantos, E.; Tomás-Barberán, F.A.; Wichers, H.J. Synthesis of the antioxidant hydroxytyrosol using tyrosinase as biocatalyst. J. Agric. Food Chem. 2001, 49, 1187-1193. [CrossRef]

11. Xu, D.-Y.; Chen, J.-Y.; Yang, Z. Use of cross-linked tyrosinase aggregates as catalyst for synthesis of L-DOPA. Biochem. Eng. J. 2012, 63, 88-94. [CrossRef]

12. Min, K.; Park, K.; Park, D.-H.; Yoo, Y.J. Overview on the biotechnological production of L-DOPA. Appl. Microbiol. Biotechnol. 2015, 99, 575-584. [CrossRef]

13. Guazzaroni, M.; Crestini, C.; Saladino, R. Layer-by-Layer coated tyrosinase: An efficient and selective synthesis of catechols. Biorg. Med. Chem. 2012, 20, 157-166. [CrossRef] [PubMed]

14. Guazzaroni, M.; Pasqualini, M.; Botta, G.; Saladino, R. A novel synthesis of bioactive catechols by layer-by-layer immobilized tyrosinase in an organic solvent medium. Chem CatChem 2012, 4, 89-99. [CrossRef] 
15. Bozzini, T.; Botta, G.; Delfino, M.; Onofri, S.; Saladino, R.; Amatore, D.; Sgarbanti, R.; Nencioni, L.; Palamara, A.T. Tyrosinase and Layer-by-Layer supported tyrosinases in the synthesis of lipophilic catechols with antiinfluenza activity. Bioorg. Med. Chem. 2013, 21, 7699-7708. [CrossRef] [PubMed]

16. Botta, G.; Delfino, M.; Guazzaroni, M.; Crestini, C.; Onofri, S.; Saladino, R. Selective Synthesis of DOPA and DOPA peptides by native and immobilized tyrosinase in organic solvent. ChemPlusChem 2013, 78, 325-330. [CrossRef]

17. Ramsden, C.A.; Riley, P.A. Tyrosinase: The four oxidation states of the active site and their relevance to enzymatic activation, oxidation and inactivation. Bioorg. Med. Chem. 2014, 22, 2388-2395. [CrossRef]

18. Deri-Zenaty, B.; Bachar, S.; Rebroš, M.; Fishman, A. A coupled enzymatic reaction of tyrosinase and glucose dehydrogenase for the production of hydroxytyrosol. Appl. Microbiol. Biotechnol. 2020, 104, 4945-4955. [CrossRef]

19. Yamada, K.; Akiba, Y.; Shibuya, T.; Kashiwada, A.; Matsuda, K.; Hirata, M. Water purification through bioconversion of phenol compounds by tyrosinase and chemical adsorption by chitosan beads. Biotechnol. Prog. 2005, 21, 823-829. [CrossRef]

20. Yamada, K.; Inoue, T.; Akiba, Y.; Kashiwada, A.; Matsuda, K.; Hirata, M. Removal of p-alkylphenols from aqueous solutions by combined use of mushroom tyrosinase and chitosan beads. Biosci. Biotechnol. Biochem. 2006, 70, 2467-2475. [CrossRef]

21. Flurkey, A.; Cooksey, J.; Reddy, A.; Spoonmore, K.; Rescigno, A.; Inlow, J.; Flurkey, W.H. Enzyme, protein, carbohydrate, and phenolic contaminants in commercial tyrosinase preparations: Potential problems affecting tyrosinase activity and inhibition studies. J. Agric. Food Chem. 2008, 56, 4760-4768. [CrossRef] [PubMed]

22. Inlow, J.K. Homology models of four Agaricus bisporus tyrosinases. Int. J. Biol. Macromol. 2012, 50, $283-293$. [CrossRef] [PubMed]

23. Ismaya, W.T.; Rozeboom, H.J.; Weijn, A.; Mes, J.J.; Fussetti, F.; Wichers, H.J.; Dijkstra, B.W. Crystal structure of Agaricus bisporus mushroom tyrosinase: Identity of the tetramer subunits and interaction with tropolone. Biochemistry 2011, 50, 5477-5486. [CrossRef] [PubMed]

24. Mauracher, S.G.; Molitor, C.; Al-Oweini, R.; Kortz, U.; Rompel, A. Latent and active abPPO4 mushroom tyrosinase cocrystallized with hexatungstotellurate (VI) in a single crystal. Acta Crystallogr. D Biol. Crystallogr. 2014, 70, 2301-2315. [CrossRef] [PubMed]

25. Matoba, Y.; Kihara, S.; Bando, N.; Yoshitsu, H.; Sakaguchi, M.; Kayama, K.; Yamagisawa, S.; Ogura, T.; Sugiyama, M. Catalytic mechanism of the tyrosinase reaction toward the $\mathrm{Tyr}^{98}$ residue in the caddie protein. PLoS Biol. 2018, 16, e3000077. [CrossRef]

26. Tsuzuki, S.; Honda, K.; Uchimaru, T.; Mikami, M.; Tanabe, K. The magnitude of the $\mathrm{CH} / \pi$ Interaction between benzene and some model hydrocarbons. J. Am. Chem. Soc. 2000, 122, 3746-3753. [CrossRef]

27. Goldfeder, M.; Kanteev, M.; Isaschar-Ovdat, S.; Adir, N.; Fishman, A. Determination of tyrosinase substrate-binding modes reveals mechanistic differences between type-3 copper proteins. Nat. Commun. 2014, 5, 4505. [CrossRef]

28. Romanovskaya, I.I.; Shesterenko, Y.A.; Sevastyanov, O.V. Elimination of phenol with the use of tyrosinase of fungi. J. Water Chem. Technol. 2009, 31, 135-138. [CrossRef]

29. Selinheimo, E.; Gasparetti, C.; Mattinen, M.-L.; Steffensen, C.L.; Buchert, J.; Kruus, K. Comparison of substrate specificity of tyrosinases from Trichoderma reesei and Agaricus bisporus. Enzym. Microb. Technol. 2009, 44, 1-10. [CrossRef]

30. Guo, M.; Lu, F.; Du, L.; Pu, J.; Bai, D. Optimization of the expression of a laccase gene from Trametes versicolor in Pichia methanolica. Appl. Microbiol. Biotechnol. 2006, 71, 848-852. [CrossRef]

31. Rucká, L.; Chmátal, M.; Kulik, N.; Petrásková, L.; Pelantová, H.; Novotný, P.; Př́hodová, R.; Pátek, M.; Martínková, L. Genetic and functional diversity of nitrilases in Agaricomycotina. Int. J. Mol. Sci. 2019, 20, 5990. [CrossRef]

32. Berman, H.M.; Westbrook, J.; Feng, Z.; Gilliland, G.; Bhat, T.N.; Weissig, H.; Shindyalov, I.N.; Bourne, P.E. The protein data bank. Nucleic Acids Res. 2000, 28, 235-242. [CrossRef] [PubMed]

33. Krieger, E.; Koraimann, G.; Vriend, G. Increasing the precision of comparative models with YASARA NOVA-A self-parameterizing force field. Proteins 2002, 47, 393-402. [CrossRef] [PubMed]

34. Matoba, Y.; Kumagai, T.; Yamamoto, A.; Yoshitsu, H.; Sugiyama, M. Crystallographic evidence that the dinuclear copper center of tyrosinase is flexible during catalysis. J. Biol. Chem. 2006, 281, 8981-8990. [CrossRef] 
35. Murphy, R.B.; Philipp, D.M.; Friesner, R.A. A mixed quantum mechanics/molecular mechanics (QM/MM) method for large-scale modeling of chemistry in protein environments. J. Comp. Chem. 2000, 21, 1442-1457. [CrossRef]

36. Kim, S.; Chen, J.; Cheng, J.T.; Gindulyte, A.; He, J.; He, S.; Li, Q.; Shoemaker, B.A.; Thiessen, P.A.; Yu, B.; et al. PubChem 2019 update: Improved access to chemical data. Nucleic Acids Res. 2019, 47, D1102-D1109. [CrossRef]

37. Humphrey, W.; Dalke, A.; Schulten, K. VMD: Visual molecular dynamics. J. Mol. Graph. Model. 1996, 14, 33-38. [CrossRef]

38. Vaught, A. Graphing with Gnuplot and Xmgr. Linux J. 1996, 1996, 7.

(C) 2020 by the authors. Licensee MDPI, Basel, Switzerland. This article is an open access article distributed under the terms and conditions of the Creative Commons Attribution (CC BY) license (http://creativecommons.org/licenses/by/4.0/). 